\title{
Functional Outcomes of Floating Knee Injuries after Surgical Management: A Comprehensive Study and Treatment Results
}

\section{Jaiganesh Veerappan*}

Assistant Professor, Department of Orthopaedics, Government Theni Medical College, K. Villaku, Theni, Tamilnadu, India

*Corresponding Author: Jaiganesh Veerappan, Assistant Professor, Department of Orthopaedics, Government Theni Medical College, K. Villaku, Theni, Tamilnadu, India.

DOI: $10.31080 /$ ASOR.2020.03.0150
Received: February 05, 2020

Published: February 24, 2020

(C) All rights are reserved by Jaiganesh

Veerappan.

\begin{abstract}
Background: Floating Knee injuries are considered as complex injuries. It ranges from simple shaft fracture to complex articular fractures, it will make a challenging task to manage. In this article we present the functional outcome of surgical stabilization of floating knee injuries and comparative analysis between FRASER type I and type II A,B,C fractures.

Objective: The aim of the study is to analyse the functional outcome of surgical stabilization of floating knee injuries and carry out a comparative analysis between FRASER types I and type II A, B, C fractures.

Methods: For this study 28 consecutive patients with ipsilateral femur and tibia fractures who presented to Casualty, Government Rajaji Hospital, Madurai Medical College, Madurai, and surgical management were included. This study is a prospective study with a minimum of 6 months follow up for the patients

Results: The mechanism of injury was road traffic accident with 34 patients. Out of the 34 patients 2 patients ended up in amputation and 4 patients were lost in the follow-up. Hence a total of 28 patients were studied. Open fractures were seen in 5 patients with femur and 10 patients with tibia. Associated injuries are for 12 patients with femur intraarticular fractures and 11 patients with tibia intraarticular fractures. From observation, there was a wide range of post-operative complications such as ARDS in one patient, infection in seven patients, delayed union in seven patients and malunion in six patients. Finally as part of end results, overall average knee range of motion was 0 to 900 . The average knee range of motion in excellent outcome group of patients was 0 - 1150 , good outcome group of patients had 0 - 1000, acceptable outcome group of patients had 0 - 900 and poor outcome group of patients had 10 - 400. Final results were validated based on Karlstorm and Olerud to grade the functional outcome of floating knee injuries.

Conclusion: Floating knee injuries occurs due to high velocity trauma. Road traffic accidents particularly two wheeler accident is the commonest cause of the injuries and highly affected is male. Many associated with other injuries such as patellar fractures, cruciate ligament injuries and vascular injuries. Appropriate management of the associated injuries, the most important factors is to determine the functional outcome on the type of fractures, nature of comminution, intraarticular extension, mode of fixation and post-operative infection, it is important to reach the effective final outcome.
\end{abstract}

Keywords: Floating Knee Injury; Femur, Tibia; Fraser Type I and Type II; Karlstorm and Olerud Scoring

\section{Introduction}

Floating knee injury is a term used to denote ipsilateral femoral and tibial metaphyseal / diaphyseal fractures. It ranges from simple shaft fracture to complex articular fractures. These injuries are extremely under heterogeneous groups, they usually occur due to very high energy trauma. These are relatively uncommon 
injuries. These are always associated with high morbidity. Most of these injuries result in some permanent disability. There are no specific guidelines for the management in operating these type of injuries. The implant choice needs to be determined depending on nature of fracture and soft tissue injuries. The incidence of floating knee injuries was reported as $2.6 \%$ of all fractures by previous medical cases. These injuries were associated with life threatening injuries such as head injury, chest injury and abdominal injuries. Other skeletal injuries were also seen in these patients. Injuries were often a combination of different fracture patterns. There was extensive soft tissue damage of the limb as well. The soft tissue injuries can also be variable from minor abrasions to grade III open injuries. Injuries to the neurovascular structures add a treacherous component to the whole picture. This often perplexes even the most experienced clinicians in the choice of management. The established principles of treatment are as follows:

1. Early and thorough debridement of the wound in case of open fractures - Damage control procedures.

2. Accurate reduction of intraarticular fractures and reduction of dislocations.

3. Stabilization of fractures with appropriate implants.

4. Concurrent management of neurovascular injury.

5. Life threatening issues - (Head, Chest and abdomen injuries) to be managed with priority

6. Primary or delayed primary closure of wounds.

7. Early mobilization of the knee joint and introduction of the functional activities of the lower limb.

The objective of this study is to analyse the functional outcome of surgical stabilization of floating knee injuries and Comparative analysis between FRASER type I and type II A, B, C fractures. The research work in this paper focus on studying the new cases, patterns and morphology of floating knee injuries, their management modalities and results. For this research study, 28 consecutive patients with ipsilateral femur and tibia fractures who presented to Casualty, Government Rajaji Hospital, Madurai Medical College, Madurai were included. It is a Prospective study with a minimum follow up of six months.

\section{Materials and Methods}

This was a prospective study conducted in Department of Orthopaedics, Govt. Rajaji Hospital, Madurai Medical College Madurai. This study is about the functional outcome of surgical stabiliza- tion of floating knee injuries using Karlstrom and Olerud's criteria and comparative analysis between Fraser's type I and Type II A.B.C. For this study 34 consecutive patients with ipsilateral femur and tibia fractures who presented to Casualty, Government Rajaji Hospital, Madurai Medical College, Madurai from Jun 2012- Nov 2014 who fulfilled the criteria were included but four patients were lost in follow up and two patients ended up in amputation. These 6 patients excluded in this scoring system. So the final study comprised of twenty eight patients. The follow up study was done at 4 weeks, 8 weeks, 12 weeks and 24 weeks. Serial x-rays and functional assessment were carried out at each visit in outpatient clinic itself using the Karlstorm and Olerud's criteria. The 28 patients were classified according to Fraser's classification. Of these 13 were type I, 3 were type IIA, 4 were type IIB and 8 were type IIC. The details of pre-operative status like mode of injury, fracture patterns, closed or open injuries and any associated injuries were also evaluated.

In this study the most common mechanism of injury was road traffic accidents (93.33\%). Among the road traffic accidents motor cycle accidents (Two wheeler accidents) (57.14\%) accounted the most. Four wheeler accidents accounted to about $33.3 \%$ and $3.57 \%$ were pedestrians. The more number of road traffic accident cases were due to high speed vehicle and roads. Twenty eight patients were included in this study, males predominated in this study ( $89.29 \%$ male, $10 \%$ female). Other similar studies in literature also describes the similar gender distribution $[1,2]$. The age distribution was from 18 years to 65 years (Mean: 36.50, Median: 36.50, Mode: 18). Skeletally immature paediatric age group was not included in the study. Right sided injuries (67.85\%) were more common than left sided injuries (39.28\%). There were totally 15 open fractures among which femur were five $(17.85 \%)$ and tibia were ten (35.71\%). The patients were classified according to Fraser's Classification for floating knee injuries. Below table 1 shows the Fraser classification of cases.

\begin{tabular}{|l|c|c|c|c|c|}
\hline $\begin{array}{l}\text { Fraser's } \\
\text { Type }\end{array}$ & Type - I & Type-Iia & Type-Iib & Type-Iic & $\begin{array}{c}\text { Total } \\
\text { Cases }\end{array}$ \\
\hline $\begin{array}{l}\text { No. Of } \\
\text { Patients }\end{array}$ & 13 & 3 & 4 & 8 & 28 \\
\hline $\begin{array}{l}\text { Percent- } \\
\text { age }\end{array}$ & $46.42 \%$ & $10.73 \%$ & $14.28 \%$ & $28.57 \%$ & $100 \%$ \\
\hline
\end{tabular}

Table 1: Fraser's Classification of Cases. 
Functional Outcomes of Floating Knee Injuries after Surgical Management: A Comprehensive Study and Treatment Results

For these cases, inclusion criteria includes: a) All adult ipsilateral femur and tibia fractures b) Both closed and open fractures c) Polytrauma patients under stable condition d) Head injury patients with GCS > 7. Exclusion criteria includes: a) Paediatric ipsilateral femur and tibia fractures b) Head injury patients with GCS < 7 c) Associated neurological injuries such as paraplegia or quadriplegia resulting from spinal injuries. When the patients presented in Casualty, primary survey of airway breathing and circulation was completed. The patients were resuscitated accordingly. Once the patient was hemodynamically stable necessary primary investigations were completed. All fractures were splinted in Thomas splint or plaster of paris slab. Open fractures and wounds were documented properly. Cultures were sent for analysis. Adequate wound wash and irrigation was completed with minimum of $5 \mathrm{~L}$ of sterile normal saline. Appropriate antibiotics and prophylactic tetanus toxoid were started.

The subject was included into the study once a diagnosis of floating knee injury was made in the emergency room. Floating knee was classified according to FRASER'S CLASSIFICATION. Open fractures were classified according to GUSTILO AND ANDERSON classification. The plan of management for the given patient was made depending on the nature of fracture, location of fracture, associated soft tissue injuries. A primary survey was made and x-rays were taken to image the entire femur and tibia with the adjacent articulations of the knee hip and ankle. Primary care was provided to all these patients and then they were operated. The patient was subjected to mobilization schedule according to associated injuries and general condition.

\section{Associated other injuries}

The Associated other injuries were observed in eighteen cases (64.28\%). Contralateral lower limb injuries were two, (7.14\%) one patient had shaft of femur fracture for which nailing has been done and another one patient had ACL injury which was managed by ligamentous reconstruction Upper limb injures were five (17.85\%) out of which four were ipsilateral and one was contralateral. Among the four ipsilateral upper limb injuries, two were distal radius fractures, one patient with clavicle fracture and one patient had humerus fracture. The two distal radius fractures were fixed with $\mathrm{k}$ wire, the clavicle was treated with conservative manner and humerus treated with nailing. The one contralateral upper limb injury was both bones fracture forearm for which open reduction and internal fixation with plating was done along with the fixation of the floating knee. Another one patient had ACL injury was treated by ligament reconstruction. Head injury was present in four (14.28\%) patients. Among these three underwent surgery. The fixation of the floating knee had to be delayed till the patients have stabilized. But the bony union of both femur and tibia in these patients after fixation was earlier than 12 weeks. Chest injury was seen in three $(10.71 \%)$ patients, two patients needed intercostal chest tube for haemothorax. One patient had brachial plexus injury on same side under physiotherapy. Table 2 shows the associated other injuries.

\begin{tabular}{|l|c|c|c|}
\hline No. & $\begin{array}{c}\text { Associated other } \\
\text { injuries }\end{array}$ & $\begin{array}{c}\text { No. } \\
\text { patients }\end{array}$ & Treatment \\
\hline & $\begin{array}{c}\text { Contralateral lower } \\
\text { limb Shaft of femur } \\
\text { ACL injury }\end{array}$ & 1 & IMIL \\
\cline { 3 - 4 } II & $\begin{array}{c}\text { Upper limb Ipsilat- } \\
\text { eral Shaft of humerus } \\
\text { Distal radius fracture } \\
\text { Clavicle fracture }\end{array}$ & 2 & $\begin{array}{c}\text { IMIL CRIF with K } \\
\text { wire Conservative }\end{array}$ \\
\hline III & $\begin{array}{c}\text { Upper limb contra- } \\
\text { lateral Both bones } \\
\text { forearm fracture }\end{array}$ & 1 & $\begin{array}{c}\text { ORIF - Plating } \\
\text { IV }\end{array}$ \\
\hline V & $\begin{array}{c}\text { Head Injury } \\
\text { mopnemothorax }\end{array}$ & 4 & $\begin{array}{c}\text { Craniotomy Conser- } \\
\text { vative-1 }\end{array}$ \\
\hline VI & Brachial plexus injury & 1 & $\begin{array}{c}\text { Intercostal drain- } \\
\text { age - 2 }\end{array}$ \\
\hline
\end{tabular}

Table 2: Associated Other Injuries.

\section{Post-operative complications}

There was one $(3.57 \%)$ patient with ARDS, required prolonged intensive care. Infection was seen in most of the open type of fractures. There were seven (25\%) cases with infection, Out of which two patients required implant removal. One Patient was MRSA positive. One patient (3.57\%) had an implant failure. Delayed union was seen in seven patients (25\%) who required bone grafting. Malunion was seen in six (26.6\%) patients, among these three patients had femur and tibia deformities and 3 patients had only tibial deformities. Table 3 shows the post-operative complications. 


\begin{tabular}{|l|c|c|c|}
\hline No. & Complication & $\begin{array}{c}\text { No of } \\
\text { Patient }\end{array}$ & Additional procedures \\
\hline I & Fat Embolism & 1 & Intensive Care \\
\hline II & $\begin{array}{c}\text { Infection } \\
(1-M R S A)\end{array}$ & 7 & $\begin{array}{c}\text { Implant removal - 2 } \\
\text { Wound debridement - 2 }\end{array}$ \\
\hline III & $\begin{array}{c}\text { Delayed Union } \\
\text { Femur -2 Tibia - 5 }\end{array}$ & 7 & Bone grafting - 2 \\
\hline IV & $\begin{array}{c}\text { Malunion Both } \\
\text { femur and tibia - } 3 \\
\text { Tibia alone }-3\end{array}$ & 6 & Follow up \\
\hline
\end{tabular}

Table 3: Post-operative complications.

Knee- range of motion

The knee range of motion was an important criteria for the functional outcome. The maximum range recorded was 0 - 1200. The minimum range recorded was 20 - 500. The average range of motion in the thirty patients was $10-900$.

\section{Fraser classification of cases}

The floating knee injuries were classified classification. Out of the 28 patients were in type IIB and 8 patients were in type IIC. The initial fixation of femur depended upon the type of fracture and the different modalities used were external fixators, plating, intramedullary nailing conservative methods. Table 4 and 5 shows the type of femur and tibia surgery. The duration of surgery ranged from 120 minutes to 330 minutes. The Mean was 202 minutes, Median was 191, and Mode was 57.555.

Function outcome

The overall functional outcome was accessed using KARLSTROM and OLERUD criteria. The results showed eleven patients
(57.19\%) with GOOD ACCEPTABLE outcome. The different variables were analysed with the final outcome in order to identify the factors which may affect the final outcome of the patients. The different variables which were correlated with the final outcome were based on a) Age of the patient b) Mode of injury c) Sex of the patient d) Side of injury e) Level of the femur fractures f) Level of the tibia fractures g) Soft tissue injury h) Femur fixation methods i) Tibia fixation methods j) Fraser's types. Below table 6 shows the functional outcome of Fraser type.

\begin{tabular}{|l|c|c|}
\hline Type of Surgery & No of Person & Percentage \\
\hline Ex Fix & 1 & $3.57 \%$ \\
\hline Plating & 9 & $32.14 \%$ \\
\hline Imil & 14 & $50 \%$ \\
\hline K Wire/Screw & 3 & $10 \%$ \\
\hline Conservative & 1 & $3.57 \%$ \\
\hline Total & 28 & $100 \%$ \\
\hline
\end{tabular}

Table 4: Femur Surgery.

\begin{tabular}{|l|c|c|}
\hline Type Of Surgery & No Of Person & Percentage \\
\hline Ex Fix & 2 & $7.14 \%$ \\
\hline Plating & 5 & $17.85 \%$ \\
\hline Imil & 9 & $32.14 \%$ \\
\hline K Wire/Screw & 2 & $7.14 \%$ \\
\hline Conservative & 10 & $35.71 \%$ \\
\hline Total & 28 & $100 \%$ \\
\hline
\end{tabular}

Table 5: Tibia Surgery.

\begin{tabular}{|l|c|c|c|c|c|c|c|}
\hline \multirow{2}{*}{ Fraser's Types } & \multirow{2}{*}{ No Of Patients } & \multirow{2}{*}{ Percentage\% } & \multicolumn{4}{|c|}{ Functional Out Come } & \multirow{2}{*}{ Total } \\
\cline { 4 - 7 } & & & Poor & Accept & Good & Excellent & \\
\hline Type I & 13 & $46.44 \%$ & 0 & 0 & 4 & 9 & 13 \\
\hline Type II A,B,C & 15 & $53.56 \%$ & 0 & 1 & 12 & 2 & 15 \\
\hline Total & 28 & 100 & 0 & 1 & 16 & 11 & 28 \\
\hline
\end{tabular}

Table 6: Functional outcome of Fraser type.

Patients from different Fraser's type injuries and their functional outcome karlstrom and oleurd criteria) were statistically significant as t- value $=3.827 \mathrm{df}=26 \mathrm{p}<0.05$. Further it can be concluded that there exists significant difference between type I and type II A, B, C.

\section{Results and Discussion}

Results Fraser Classification and functional outcome: It clearly indicate that the mean SD and $\mathrm{F}$ value for the patients from different types for their variables - (karlstrom and oleurd). It has been observed that patients from Type I have higher score (mean 27) followed by type IIA, IIC and IIB this observation revealed by SIG- 
Functional Outcomes of Floating Knee Injuries after Surgical Management: A Comprehensive Study and Treatment Results

NIFICANT the F-value 0.05 level, $\mathrm{t}$ value $=3.827 \mathrm{df}=26 \mathrm{p}<0.05$. Further it can be concluded that there exist significant difference between type I and type II (A, B, C) (post hoc test).

Fixation of femur and functional outcome: The definitive fixation of femur, IMIL method has produced higher functional outcome than other method. Their differences are statistically SIGNIFICANT. ( $F$ value $=3.601 \mathrm{df}=4.23 \mathrm{p}<0.05$ significant).

Fixation of Tibia and Functional Outcome: The definitive fixation of tibia, IMIL method has produced higher functional outcome than other methods. Their differences are statistically SIGNIFICANT $($ F ratio $=4.599 \mathrm{df}=4.23 \mathrm{p}<0.05$ significant ).

Level of Fractures in Femur and Functional Outcome: Level of the fracture in tibia and their functional outcome are statistically SIGNIFICANT $\mathrm{p}<0.05$ as fractures shaft do well than others.

Comparative analysis with other studies: This study was compared with various studies in the existing literature and results are as follows:

\begin{tabular}{|l|c|c|c|c|c|}
\hline Name of Study & $\begin{array}{c}\text { Total Number } \\
\text { patients }\end{array}$ & Excellent & Good & Acceptable & Poor \\
\hline Fraser., et al. [2] & 63 & 3 & 15 & 30 & 15 \\
\hline Schiedts., et al. [3] & 18 & 4 & 7 & - & 7 \\
\hline Hee., et al. [4] & 89 & 6 & 53 & 25 & 4 \\
\hline Anoop Kumar., et al. [5] & 42 & 7 & 14 & 14 & 7 \\
\hline Ulfin Rethnam., et al. [6] & 29 & 15 & 9 & 2 & 3 \\
\hline Our Study & 28 & 11 & 16 & 1 & 0 \\
\hline
\end{tabular}

Table 7: Comparative Result Analysis with Existing works.

Excellent Outcome: There were 11 patients (39.28\%) with Excellent outcome in whom 7 patients had both femur and tibia nailing, 2 patients had femur nailing and ex fixator for tibia, 1 patient had femur nailing and conservative management of tibia,1 patient had condylar screw fixation for femur and nailing for tibia. All these patients had no pain or any deformity.

Good Outcome: Among the Good outcomes, six patients had intermittent knee pain but not severe. These patients had changed their jobs after the accident.

Acceptable Outcome: Acceptable outcome was seen in 1 $(3.75 \%)$ patients. The average range of motion at the knee for these patients was $0-900$. The walking distance of these patients were restricted.

As per KARLSTROM AND OLERUD CRITERIA in this study, there was no poor outcome. But two patients ended up in amputation. Since it was the poor result. It could not be included in this study.

Below figure 1 shows the sample case on functional outcome of floating knee injury This study was conducted in the Department of Orthopaedics, Govt. Rajaji Hospital, Madurai Medical college, Madurai. This study was a prospective study. The study period was from June 2012 to November 2013. The study included 34 consecutive patients with Ipsilateral femur and tibia fracture and who fulfilled the criteria. Out of the 34 patients 2 patients ended up in amputation and 4 patients were lost in the follow-up. Hence a total of 28 patients were studied. The minimum follow up was six months. The age of the patients ranged from 18 years to 65 years, the largest age group was 31 years to 40 years, which had nine (30\%) patients. Males predominated in this study. There were 25 (89.29\%) males. Right sided injury was more common - 19 patients (60.71\%). Road traffic accident was the commonest cause. Among these, two wheeler accidents were more common - 16patients (57.14\%). Open fractures were seen in 5 (17.85\%) femur and 10 (35.71\%) tibia. There were 12 (42.85\%) femur intraarticular fractures and 11 (39.28\%) tibia intraarticular fractures. Fractures involving intraarticular extension in femur determined the functional outcome in floating knee injuries Fraser's type II B, C. Type I Fraser's floating knee injuries were the commonest 13 cases. (46.42\%). External fixator was applied to $1(3.57 \%)$ femur and $2(7.14 \%)$ tibia. Plating was done in $9(32.14 \%)$ femur and 5 (17.85\%) tibia. Intramedullary nailing 
was done in 14 (50\%) femur fractures. Tibial Nailing was done in $9(32.14 \%)$ patients. $\mathrm{K}$ wire and screw fixation done for 3 femur fractures and 2 tibia fractures. Fraser's type I injuries treated with nailing had excellent (32.14\%) outcome. Fraser's type II injuries treated with plating had good $(21.43 \%)$ outcome. There was a wide range of post-operative complications such as ARDS in one patient $(3.57 \%)$, infection in seven patients $(25 \%)$, delayed union in seven patients $(25 \%)$ and malunion in six patients $(21.43 \%)$. Post op infections 7 patients (25\%) had prolonged hospital stay and delayed rehabilitation which also affected functional outcome. The functional outcome was excellent in 11 patients (39.29\%), Good in 16 patients (57.14\%), Acceptable in 1 Patient (3.57\%). Comparing Fraser's type I and type II Fraser's type I had excel- lent outcome 9 patients (32.14\%) and good outcome in 4 patients (14.28\%). Fraser's type II had good outcome 12 patients (42.86\%) followed by excellent outcome in 2 patients (7.14\%). The statistical correlation showed that there was significant relation of various variables with the functional outcome. The average time period for bony union of femur were seventeen weeks and that of tibia was thirteen weeks. The initiation of weight bearing range from 4 weeks to 25 weeks with them for a mean of 11 weeks. The overall average knee range of motion was 0 to 900 . The average knee range of motion in excellent outcome group of patients was 0 - 1150, good outcome group of patients had 0 - 1000, acceptable outcome group of Patients had 0 - 900 and poor outcome group of patients had $10-400$.

CASE - 1
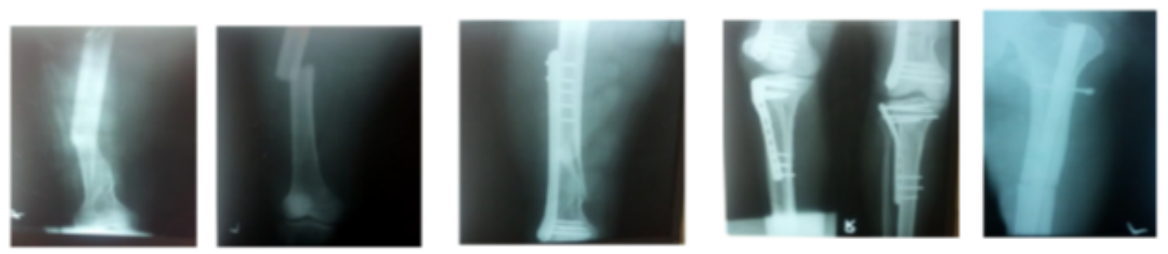

Pre-op

Pre-op

Post-op -12 wks

Post-op -12 wks

Post-op -12 wks
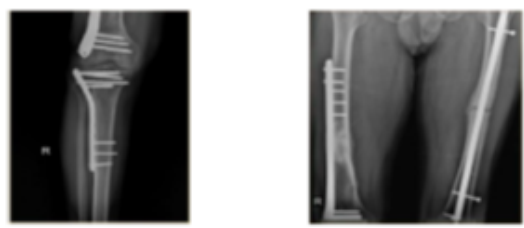

Post-op -12 wks
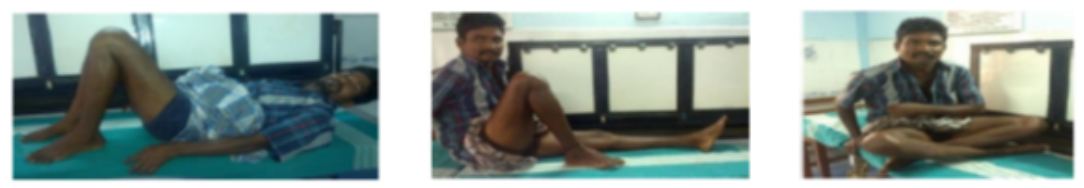

Functional outcome

Figure 1: Illustrates the functional outcome of floating knee injury. 


\section{Conclusion}

This study was intended to analyse the functional outcome of major velocity trauma resulting in floating knee injuries presented Govt. Rajaji hospital, Madurai. There were many post-operative complications like ARDS, infection, delayed union and malunion. Fraser's type I floating knee injuries, in whom primary nailing had excellent and good result. Intraarticular fractures involving femur resulted with inferior results than intraarticular fractures involving tibia. The most important factors which determine the functional outcome were the type of fractures, nature of comminution, intraarticular extension, mode of fixation and post-operative infection. Karlstorm and Olerud criteria is an effective scoring system to grade the functional outcome of floating knee injuries. Comparing Fraser's type 1 floating knee injuries have better functional outcome than Fraser's type II A, B, C.

\section{Bibliography}

1. Karlstrom G., et al. "Ipsilateral fracture of the femur and tibia". Journal of Bone Joint Surgery 59.2. (1977): 240-243.

2. Fraser RD., et al. "Ipsilateral fracture of the femur and tibia". Journal of Bone Joint Surgery 60.4 (1978): 510-515.

3. Schiedts D., et al. "Ipsilateral fractures of the femoral and tibial diaphysis". Revue de Chirurgie Orthopédique et Réparatrice de lAppareil 82.6 (1996): 535-540.

4. Hee HT., et al. "Predictors of outcome of floating knee injuries in adults: 89 patients followed for 2-12 years". Acta Scientific Orthopaedics Journal 72.4 (2001): 385-394.

5. Anoop Kumar., et al. "Ipsilateral fracture of femur and tibia, treatment and functional outcome". Journal K Science: Journal of Medical Education and Research 8.1 (2006): 42-44.

6. Rethnam U. "Single incision nailing of the floating knee-do we ignore the knee ligaments". International Journal of Orthopedics 30.4 (2006): 311.

\section{Assets from publication with us}

- Prompt Acknowledgement after receiving the article

- Thorough Double blinded peer review

- Rapid Publication

- Issue of Publication Certificate

- High visibility of your Published work

Website: https://www.actascientific.com/

Submit Article: https://www.actascientific.com/submission.php

Email us: editor@actascientific.com

Contact us: +919182824667

Citation: Jaiganesh Veerappan. “Functional Outcomes of Floating Knee Injuries after Surgical Management: A Comprehensive Study and Treatment Results". Acta Scientific Orthopaedics 3.3 (2020): 16-22. 